\title{
LOADING AND DEFORMATION PROGRESSION DURING OPEN FORGING OF HOLLOW CYLINDRICAL BLANKS
}

\author{
Elkholy, A. H.; Falah, A. H.; Majeed, M. A. \& Almutairi, D. M. \\ Mechanical Engineering Department, College of Engineering and Petroleum, Kuwait University \\ P. O. Box 5969, Safat 13060, Kuwait \\ E-Mail: kholy1@gmail.com
}

\begin{abstract}
A solution for a hollow cylindrical blank with a velocity field derived from the equations of equilibrium and compatibility conditions is obtained. The solution, accounts for both platen interfacial friction and the blank geometry. The platens were assumed as flat bodies moving normal to the blank surface. The problem is solved by the upper-bound approach, with the assumption of constant shear factor (average coefficient of friction) between platens and blank. The radius of the blank which does not experience deformation during the forging process is referred to as the neutral radius, and was determined by power minimization. The neutral radius as well as the friction coefficient at the blank interface were found to play an important role in determining the average forging pressure and the blank deformation from initial to final configurations.

(Extended paper from the ICAT 2008 Conference, Ptuj, Slovenia, 17-18 September 2008.)
\end{abstract}

Key Words: Forging, Deformation, Interfacial Pressure, Upper Bound Approach

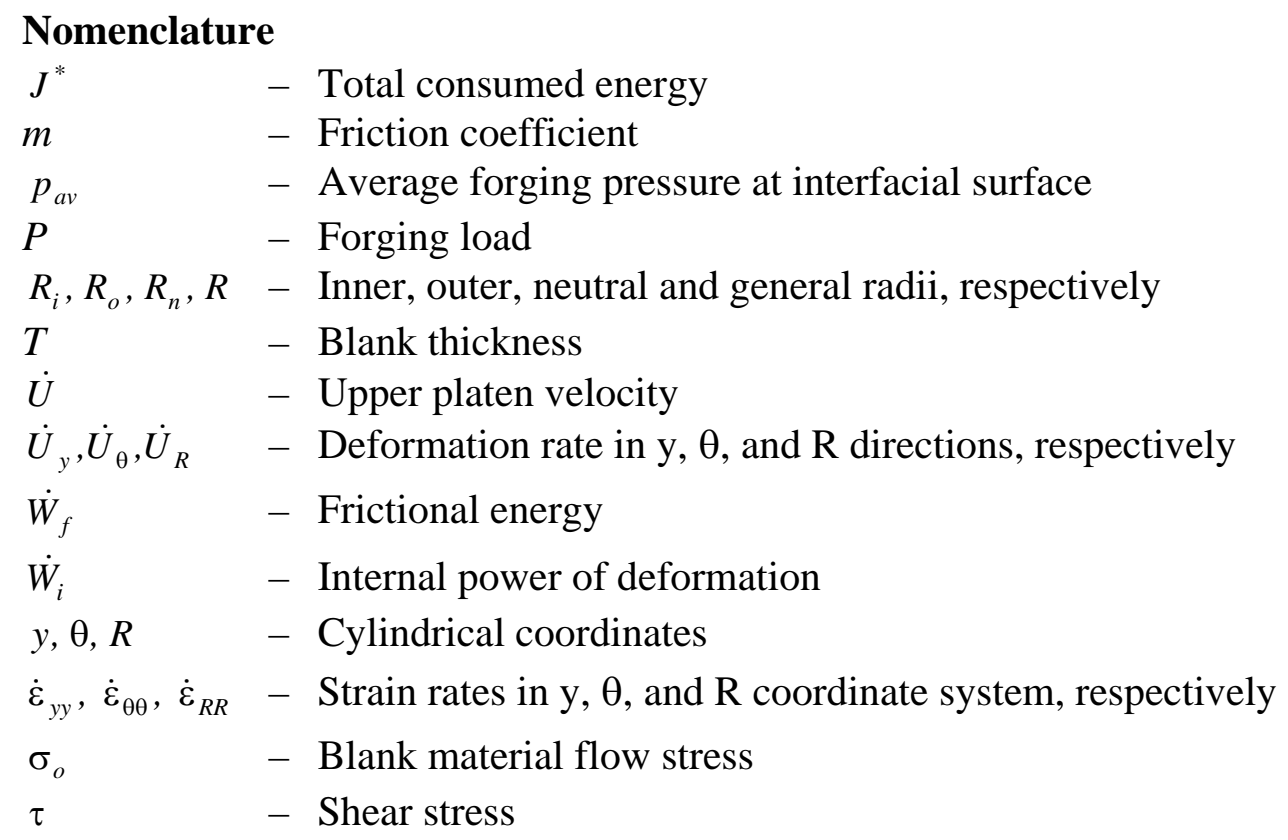

\section{INTRODUCTION}

During the last few years, forged metal components have assumed an important position in industry, as they are being used successfully in a wide range of applications. Both the mechanical and metallurgical properties of forged metal components compare favourably, and are even superior, to those of cast and machined ones [1-4]. Quite frequently, bulk processing of components by forging is used as a convenient method of reducing or eliminating the 
porosity from cast or machined products. The process is attractive because it avoids a large number of production steps, high scrap losses and high-energy consumption. In the forging technology, cylindrical blanks are usually used as starting materials in the forming processes.

Although a considerable amount of work has been reported recently on the various technological aspects of the industrial processing of cylindrical blanks [5-9], no systematic attempt has been made so far to study the processing load and deformation characteristics during forging of such blanks. Prediction of occurrence of defects in forged products requires understanding of the mechanics of deforming bodies and knowledge of strain and strain rate distributions that take place during the forging process.

On the other hand, the relative velocity between the blank and the platen surface together with high interfacial pressure and/or deformation modes contribute to the conditions essential for both the final deformed shape of the product and the deformation progression [10].

This paper reports a study on forging of circular blanks between two flat platens (Fig. 1). The main objective of the study is to formulate a velocity model and deformation, investigate the nature of flow of the blank material, and determine the required load to complete the forging process. It is expected that this study will be of great importance for the assessment of platen loads and product quality during forging of cylindrical blanks at different platen speeds.

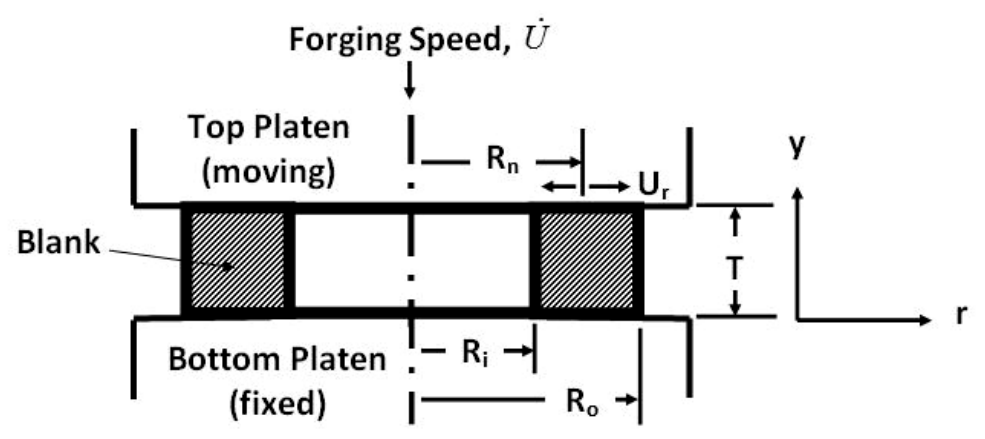

Figure 1: Forging assembly and nomenclature.

\section{VELOCITY FIELD AND STRAIN RATE}

The forging of the hollow cylindrical blank between two parallel platens is shown in Fig. 1 . The platens are considered rigid flat bodies moving normal to the blank surface with a constant velocity $\dot{U}$ as shown in the figure. The radius of the blank which remains unchanged during deformation is the neutral radius $R_{n}$. Shear factor $\mathrm{m}$ which is the average coefficient of friction between the platens and the blank, is assumed constant in the analysis. The velocity field that satisfies the volume-constancy requirement and the geometrical boundary conditions is:

$$
\begin{gathered}
\dot{U}_{y}=\frac{y}{T} \dot{U} \\
\dot{U}_{\theta}=0 \text { (because of axial symmetry) } \\
\dot{U}_{R}=-\frac{1}{2} \frac{\dot{U}}{T} R\left[1-\left(\frac{R_{n}}{R}\right)^{2}\right]
\end{gathered}
$$

The strain rates calculated from (1) are: 


$$
\begin{gathered}
\dot{\varepsilon}_{R R}=\frac{\partial \dot{U}_{R}}{\partial R}=-\frac{1}{2} \frac{\dot{U}}{T}\left[1+\left(\frac{R_{n}}{R}\right)^{2}\right], \dot{\varepsilon}_{\theta \theta}=\frac{\dot{U}_{R}}{R}=-\frac{1}{2} \frac{\dot{U}}{T}\left[1-\left(\frac{R_{n}}{R}\right)^{2}\right] \\
\dot{\varepsilon}_{y y}=\frac{\dot{U}}{T}=\text { constant, } \dot{\varepsilon}_{R \theta}=\dot{\varepsilon}_{\theta y}=\dot{\varepsilon}_{y R}=0
\end{gathered}
$$

Eq. (1) and (2) assume no bulging so that concentric cylindrical surfaces remain cylindrical in the deformed body and planes normal to the axis of symmetry retain this property.

\section{INTERNAL POWER OF DEFORMATION}

The internal power of deformation as given in [11] is:

$$
\dot{W}_{i}=\frac{2}{\sqrt{3}} \sigma_{0} \int_{v} \sqrt{\frac{1}{2} \dot{\varepsilon}_{i j} \dot{\varepsilon}_{i j}} d v
$$

where:

$$
d v=2 \pi R \cdot d R \cdot d y .
$$

Using the value of strain rate from (2), integration of (3) gives:

$$
\dot{W}_{i}=-\frac{\pi}{\sqrt{3}} \sigma_{0} \dot{U} R_{n}^{2}\left[\sqrt{1+3\left(\frac{R_{o}}{R_{n}}\right)^{4}}-\sqrt{1+3\left(\frac{R_{i}}{R_{o}}\right)^{4}\left(\frac{R_{o}}{R_{n}}\right)^{4}}-\ln \left|\left(\frac{R_{i}}{R_{o}}\right)^{2} \cdot \frac{1+\sqrt{1+3\left(\frac{R_{o}}{R_{n}}\right)^{4}}}{1+\sqrt{1+3\left(\frac{R_{i}}{R_{o}}\right)^{4} \cdot\left(\frac{R_{o}}{R_{n}}\right)^{4}}}\right|\right]
$$

\section{ENERGY DISSIPATION DUE TO FRICTION}

The frictional energy loss is given by:

$$
\dot{W}_{f}=\int_{s} \tau|\Delta v| d s
$$

where $|\Delta v|$ is the velocity difference between platens and the blank in the direction of shear and parallel to the platen surface, i.e.

$$
\begin{aligned}
\Delta v=\left|\dot{U}_{R}\right| & =\left|\frac{1}{2} \frac{\dot{U}}{\mathrm{~T}} R\left[1-\left(\frac{R_{n}}{R}\right)^{2}\right]\right| \\
\tau=m \frac{\sigma_{o}}{\sqrt{3}} \quad 0 & \leq m \leq 1, \quad d s=2(2 \pi R) d R
\end{aligned}
$$

where $\sigma_{0}$ is the material flow stress. Two separate expressions are obtained for $\dot{W}_{f}$, depending on whether $R_{n}$ is less or greater than $R_{i}$.

When $R_{n} \leq R_{i}$ :

$$
\dot{W}_{f}=-\frac{2}{3 \sqrt{3}} \pi m \sigma_{0} \frac{\dot{U}}{T} R_{n}^{3}\left[\left(\frac{R_{o}}{R_{n}}\right)^{3}-\left(\frac{R_{i}}{R_{n}}\right)^{3}-3\left(\frac{R_{o}}{R_{n}}-\frac{R_{i}}{R_{n}}\right)\right]
$$


When $R_{i} \leq R_{n} \leq R_{o}$ :

$$
\dot{W}_{f}=-\frac{2}{3 \sqrt{3}} \pi m \sigma_{0} \frac{\dot{U}}{T} R_{n}^{3}\left[4-3\left(\frac{R_{i}}{R_{n}}+\frac{R_{o}}{R_{n}}\right)+\left(\frac{R_{i}}{R_{n}}\right)^{3}+\left(\frac{R_{o}}{R_{n}}\right)^{3}\right]
$$

\section{TOTAL ENERGY}

For plastic deformation of the blank, the total energy consumed is given by:

$$
J^{*}=W_{i}+W_{f}
$$

Therefore;

when $R_{n} \leq R_{i}$ :

$$
\begin{aligned}
J^{*}= & -\frac{\pi}{\sqrt{3}} \sigma_{0} \dot{U} R_{n}^{2}\left\{\sqrt{1+3\left(\frac{R_{o}}{R_{n}}\right)^{4}}-\sqrt{1+3\left(\frac{R_{i}}{R_{o}}\right)^{4}\left(\frac{R_{o}}{R_{n}}\right)^{4}}\right. \\
& -\ln \left|\left(\frac{R_{i}}{R_{o}}\right)^{2} \cdot \frac{1+\sqrt{1+3\left(R_{o} / R_{n}\right)^{4}}}{1+\sqrt{1+3\left(R_{i} / R_{o}\right)^{4}\left(R_{o} / R_{n}\right)^{4}}}\right| \\
& \left.+\frac{2}{3} m \frac{R_{n}}{T}\left[\left(\frac{R_{o}}{R_{n}}\right)^{3}-\left(\frac{R_{i}}{R_{n}}\right)^{3}-3\left(\frac{R_{o}}{R_{n}}-\frac{R_{i}}{R_{n}}\right)\right]\right\},
\end{aligned}
$$

when $R_{i} \leq R_{n} \leq R_{o}$ :

$$
\begin{aligned}
J^{*}= & -\frac{\pi}{\sqrt{3}} \sigma_{0} \dot{U} R_{n}^{2}\left[\sqrt{1+3\left(\frac{R_{o}}{R_{n}}\right)^{4}}-\sqrt{1+3\left(\frac{R_{i}}{R_{o}}\right)^{4}\left(\frac{R_{o}}{R_{n}}\right)^{4}}\right. \\
& -\ln \left|\left(\frac{R_{i}}{R_{o}}\right)^{2} \frac{1+\sqrt{1+3\left(R_{o} / R_{n}\right)^{4}}}{1+\sqrt{1+3\left(R_{i} / R_{o}\right)^{4}\left(R_{o} / R_{n}\right)^{4}}}\right| \\
+ & \left.\frac{2}{3} m \frac{R_{n}}{T}\left\langle 4+\left(\frac{R_{o}}{R_{n}}\right)^{3}+\left(\frac{R_{i}}{R_{n}}\right)^{3}-3\left(\frac{R_{o}}{R_{n}}+\frac{R_{i}}{R_{n}}\right)\right\rangle\right]
\end{aligned}
$$

It is clear that $J^{*}$ is a function of many variables and may be expressed as follows:

$$
J^{*}=f\left(\sigma_{0}, \dot{U}, \frac{R_{i}}{R_{o}}, \frac{R_{n}}{R_{o}}, m \frac{R_{o}}{T}\right)
$$

and that $J^{*}$ should equal the energy supplied by the platens, i.e.:

$$
\begin{gathered}
J^{*}=P \dot{U} \\
=\pi\left(R_{o}{ }^{2}-R_{i}^{2}\right) p_{\text {ave }} \dot{U}
\end{gathered}
$$

where $P$ is the forging load and $p_{\text {ave }}$ is the average pressure at the interfacial surface. 


\section{DETERMINATION OF NEUTRAL RADIUS $\boldsymbol{R}_{\underline{n}}$}

The value of the neutral radius $R_{n}$ is determined by minimizing the expression for $J^{*}$. This is obtained by differentiating $J^{*}$ with respect to $R_{n}$ and equating the result to zero, i.e.:

$$
\frac{\partial J^{*}}{\partial R_{n}}=0
$$

Therefore,

when $R_{n} \leq R_{i}$, Eq. (14) yields:

$$
\left(\frac{R_{n}}{R_{o}}\right)^{2}=\frac{\sqrt{3}}{2} \frac{1-\left(R_{i} / R_{o}\right)^{4} x^{2}}{\sqrt{x(x-1)\left[1-\left(R_{i} / R_{o}\right)^{4} x\right]}}
$$

where $x=\left\{\frac{R_{o}}{R_{i}} \exp \left[-m \frac{R_{o}}{T}\left(1-\frac{R_{i}}{R_{o}}\right)\right]\right\}^{2}$

When $R_{i} \leq R_{n} \leq R_{o}$ :

$$
\frac{R_{n}}{R_{o}}=\frac{2 \sqrt{3} m R_{o} / T}{\left(R_{o} / R_{i}\right)^{2}-1}\left\{\sqrt{1+\frac{\left(1+R_{i} / R_{o}\right)\left[\left(R_{o} / R_{i}\right)^{2}-1\right]}{2 \sqrt{3} m R_{o} / T}}-1\right\}
$$

It is clear from Eq. (15) and (16) that the term $m R_{o} / T$ which appears as a variable in the calculation of the neutral radius, includes both the friction coefficient and some of the blank geometry.

\section{AVERAGE FORGING PRESSURE}

The average forging pressure $p_{\text {ave }}$ was expressed as a ratio of the blank material flow stress $\sigma_{0}$. This ratio was determined from Eq. (10) or (11) and (13) as follows:

when $R_{n} \leq R_{i}$ :

$$
\begin{gathered}
\frac{p_{\text {ave }}}{\sigma_{0}}=\frac{1}{1-\left(R_{i} / R_{o}\right)^{2}}\left\{\sqrt{1+\frac{1}{3}\left(\frac{R_{n}}{R_{o}}\right)^{4}}-\sqrt{\left(\frac{R_{i}}{R_{o}}\right)^{4}+\frac{1}{3}\left(\frac{R_{n}}{R_{o}}\right)^{4}}\right. \\
\left.+\frac{2}{3 \sqrt{3}} m \frac{R_{o}}{T}\left[1-\left(\frac{R_{i}}{R_{o}}\right)^{3}\right]\right\}
\end{gathered}
$$

when $R_{i} \leq R_{n} \leq R_{o}$ :

$$
\begin{gathered}
\frac{p_{\text {ave }}}{\sigma_{0}}=\frac{1}{1-\left(R_{i} / R_{o}\right)^{2}}\left\{\sqrt{1+\frac{1}{3}\left(\frac{R_{n}}{R_{o}}\right)^{4}}-\sqrt{\left(\frac{R_{i}}{R_{o}}\right)^{4}+\frac{1}{3}\left(\frac{R_{n}}{R_{o}}\right)^{4}}\right. \\
\left.+\frac{2}{3 \sqrt{3}} m \frac{R_{o}}{T}\left[1+\left(\frac{R_{i}}{R_{o}}\right)^{3}-2\left(\frac{R_{n}}{R_{o}}\right)^{3}\right]\right\}
\end{gathered}
$$




\section{RESULTS AND DISCUSSIONS}

The change in blank geometry as a result of continuously increasing the applied forging pressure is presented in this section in some detail. All results are presented in dimensionless form to ease the use of either the British or the SI system units. Fig. 2 outlines the effect of both the friction coefficient $m$ and thickness ratio $R_{o} / T$ on the location of the neutral radius $R_{n}$. The figure indicates that increasing the friction coefficient-thickness ratio parameter $m R_{o} / T$ results in increasing the neutral radius ratio $R_{n} / R_{i}$ for all ratios of inner to outer radii $R_{i} / R_{o}$. This may be interpreted further as follows: for higher friction coefficients between the blank and platen surfaces, or higher thickness ratio parameter $R_{o} / T$, the neutral radius shifts outwards towards and eventually exceeds the inner radius. Furthermore, the figure indicates that increasing the inner to outer radii ratio results in decreasing the $R_{n} / R_{o}$ ratio; i.e. the neutral radius is closer to the inner surface.

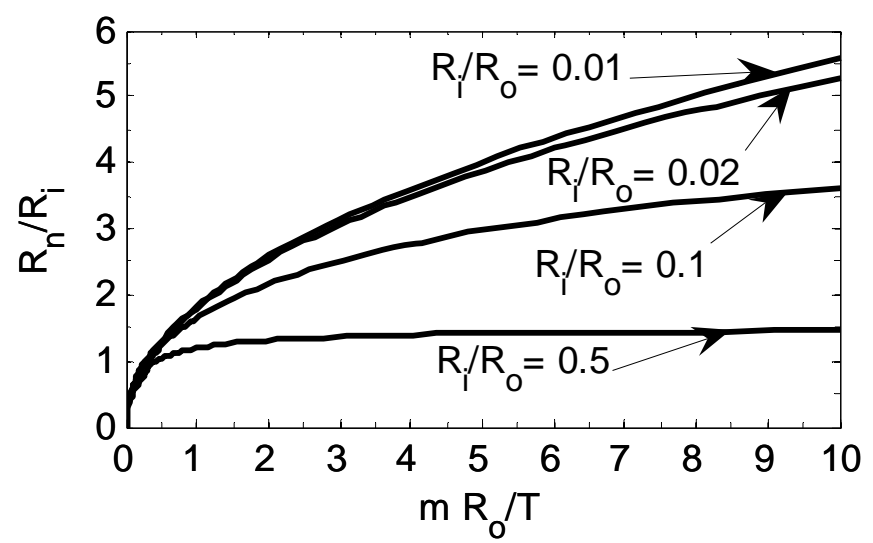

Figure 2: Variation of $R_{n} / R_{i}$ ratio with $m R_{o} / T$ ratio at different $R_{i} / R_{o}$ ratios.

Fig. 3, on the other hand, presents similar results as those outlined in Fig. 2 from another perspective. Smaller $R_{i} / R_{o}$ ratios tend to push the neutral radius outwards regardless of the $m R_{o} / T$ ratio. Nevertheless, for higher $R_{i} / R_{o}$ ratios, the neutral radius is always comparable with the inside radius irrespective of the magnitude of the $m R_{o} / T$ ratio.

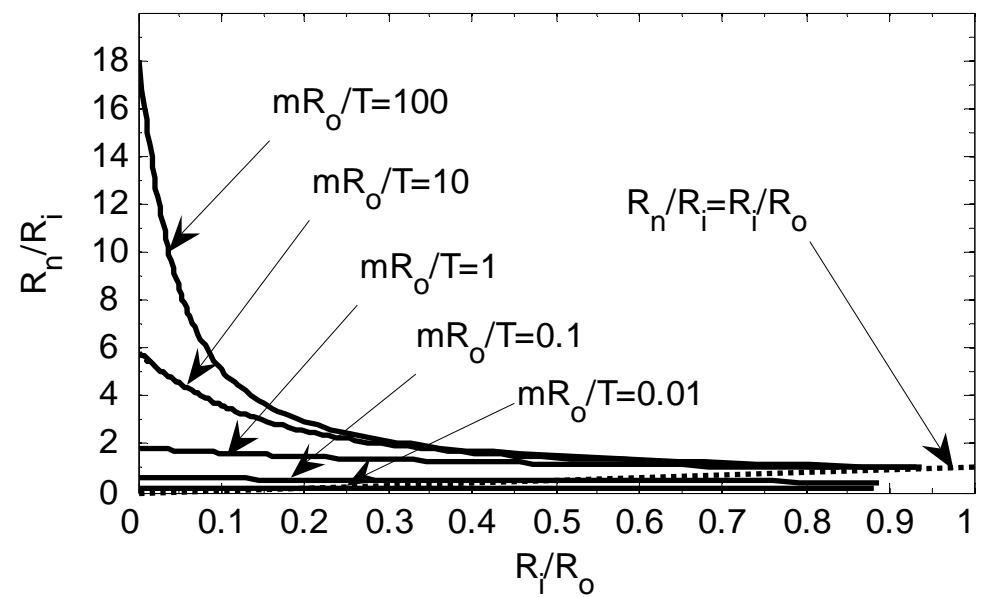

Figure 3: Variation of $R_{n} / R_{o}$ ratio with $R_{i} / R_{o}$ ratio at different $m R_{o} / T$ ratios. 
The required average forging pressure at interfacial surface $p_{a v}$ was found to depend upon the blank geometry, friction coefficient, and the blank material flow stress $\sigma_{o}$, as shown in Figs. 4-6. Fig. 4 shows that forging quasi-solid blanks (small $R_{i} / R_{o}$ ratio), requires higher pressure than that required to forge blanks with higher $R_{i} / R_{o}$ ratio. The pressure is minimum as $\mathrm{R}_{\mathrm{i}} / \mathrm{R}_{\mathrm{o}}$ ratio approaches unity (thin walled blanks). It is also clear from Fig. 4 that blanks with higher $m R_{o} / T$ ratio require higher forging pressure than those with smaller ratios.

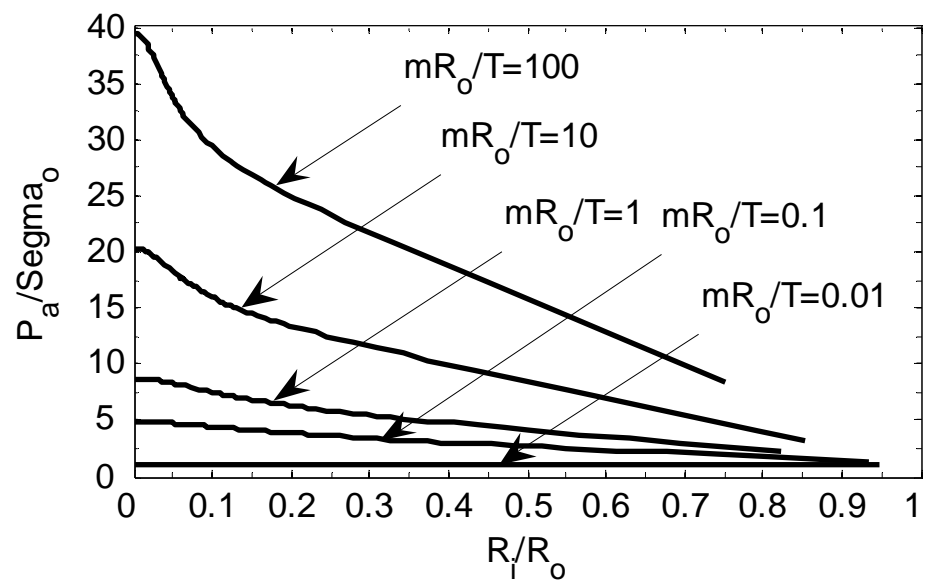

Figure 4: Relative average pressure and $R_{i} / R_{o}$ at different $m R_{o} / T$ ratios.

Fig. 5, on the other hand, shows the relationship between relative forging pressure and friction coefficient-thickness ratio parameter is nearly linear for all values of $R_{i} / R_{o}$. As either $m$ or $R_{o} / T$ increases, $p_{a v} / \sigma_{o}$ increases. That is, high friction coefficient requires high forging pressure. Also, as the sample continues to deform $\left(R_{o}\right.$ increases and $T$ decreases), higher pressure is required to forge the blank.

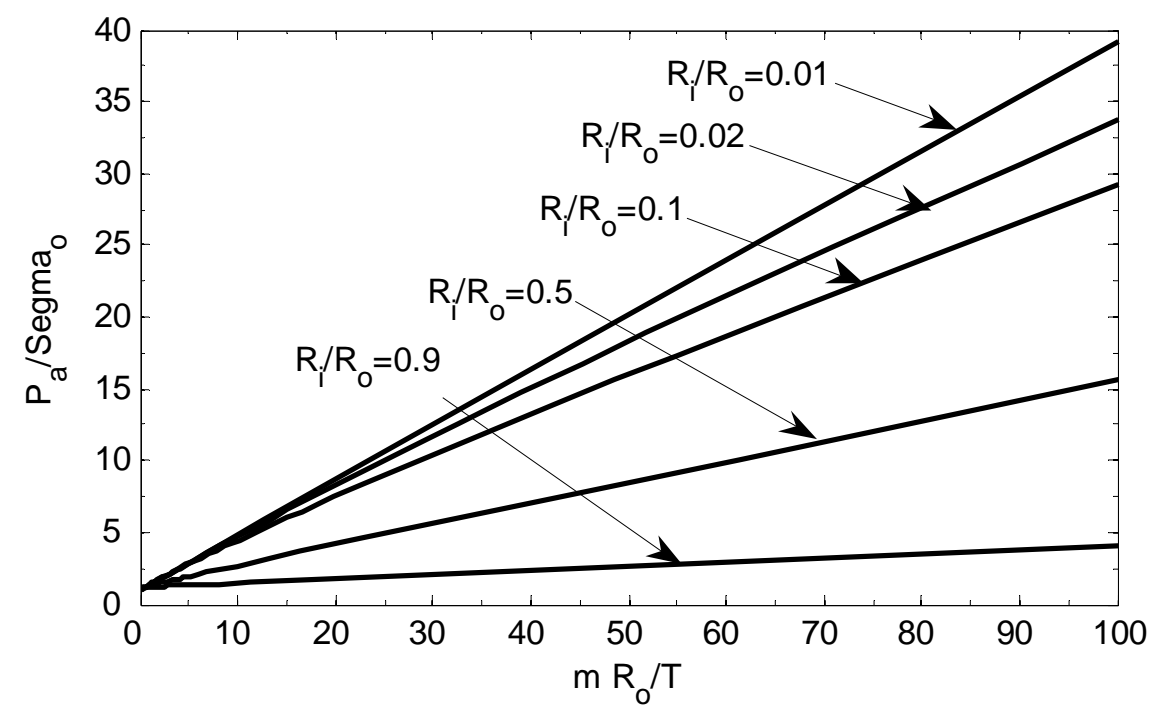

Figure 5: Variation of relative average pressure with $m R_{o} / T$ ratio at different $R_{i} / R_{o}$ ratios.

Fig. 6 outlines the relationship between forging relative pressure and friction coefficient for given outside radius to thickness ratio and inside to outside radius ratio, as shown, i.e., 
$R_{i} / R_{o}=0.1$ and $R_{o} / T$ ratio ranges from 6 to 30 as shown. In general, one can state that increasing the friction coefficient between blank interface and platen, requires high forging pressure. This explains the reason behind the recommendations made by the forging manufacturers to machine finish blank surfaces and to use proper lubricant in order to reduce the pressure (and consequently the power) requirements for blank processing. Moreover, as the blank gets further deformed ( $R_{o} / T$ increases), more pressure is needed to deform the blank.

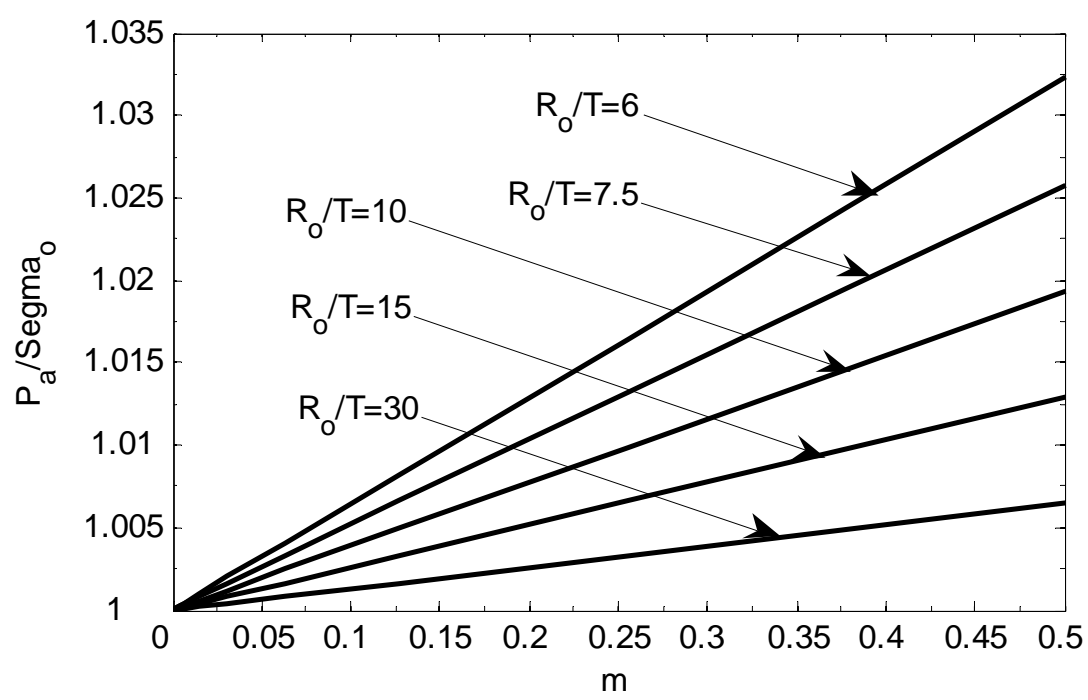

Figure 6: Variation of relative average pressure with friction coefficient at different $R_{o} / T$ ratios $\left(R_{i} / R_{o}=0.1\right)$.

\section{NUMERICAL EXAMPLE}

A typical numerical example is worked out in which a disk with original dimensions $R_{i}=30 \mathrm{~mm}, R_{o}=60 \mathrm{~mm}, T=6 \mathrm{~mm}, m=0.03$ and a constant velocity of upper platen of $\dot{U}=-1 \mathrm{~mm} / \mathrm{s}$ (downwards) was taken for analysis. By Eq. (1) the outer- and inner-radius velocities are:

$$
\begin{aligned}
& \left.\dot{U}_{R}\right|_{R=R_{O}}=-\frac{1}{2} \frac{U}{T} R_{o}\left[1-\left(\frac{R_{n}}{R_{o}}\right)^{2}\right] \\
& \left.\dot{U}_{R}\right|_{R=R_{i}}=-\frac{1}{2} \frac{U}{T} R_{i}\left[1-\left(\frac{R_{n}}{R_{i}}\right)^{2}\right]
\end{aligned}
$$

where $R_{n}$ is found from either Eq. (15) or Eq. (16). Fig. 3 is also useful in this regard. At the onset of deformation, Fig. 7 suggests that, for the given geometry and platen speed, the neutral radius $R_{n}$ is always less than the inner radius regardless of the upper platen speed. As deformation continues, the neutral radius becomes more than the inner radius and the latter would start to decrease momentarily. 
$@ U=1 \mathrm{~mm} / \mathrm{s}$

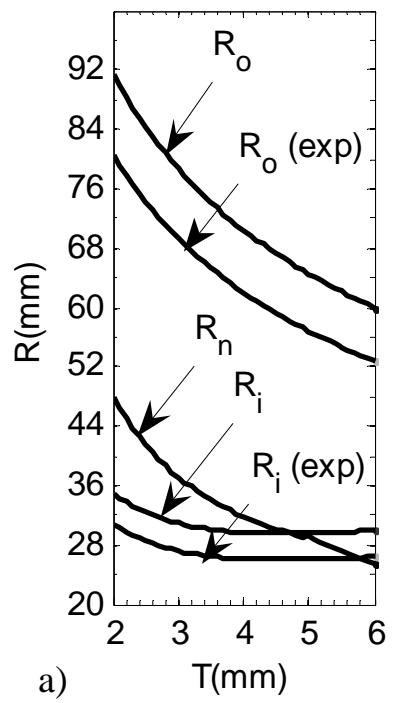

(a) $\mathrm{U}=10 \mathrm{~mm} / \mathrm{s}$

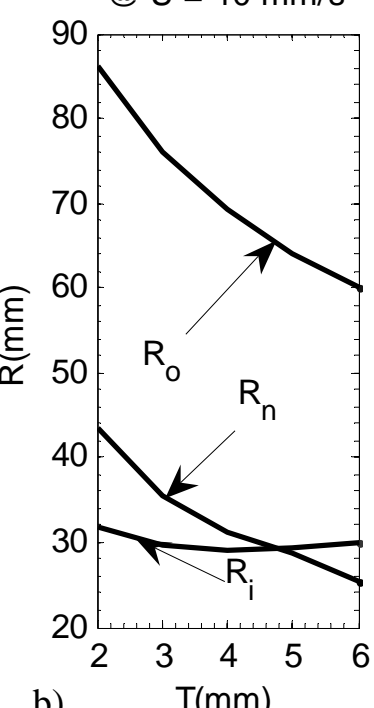

b) $\quad \mathrm{T}(\mathrm{mm})$
@ U $=20 \mathrm{~mm} / \mathrm{s}$

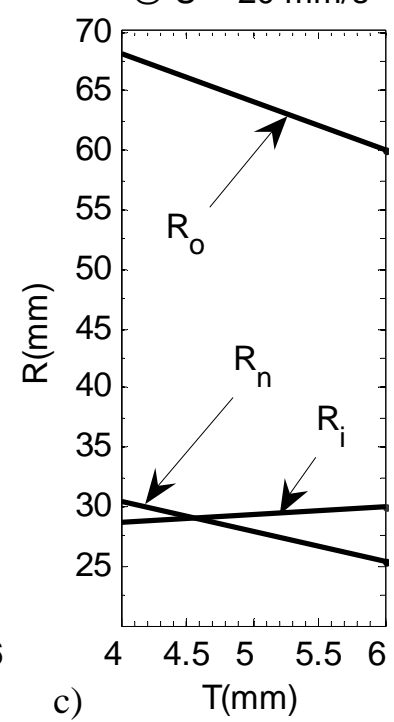

Figure 7: Blank deformation at deformation upper platen velocities.

The change in blank dimensions after a time increment of, say, $\Delta t=0.1$ second, is determined as follows:

$$
\Delta T=\dot{U} \Delta t, \quad \Delta R_{o}=\left.\dot{U}_{R}\right|_{R=R_{o}} \Delta t, \quad \Delta R_{i}=\left.\dot{U}_{R}\right|_{R=R_{i}} \Delta t
$$

From the new dimensions and by Eq. (15) and (16) or Fig. 3, the new position of the neutral point is obtained. The process is then repeated for the next $\Delta t=0.1$ second and continued until the final thickness $T_{2}$ has been reached. The smaller the increments, the more accurate are the results. A typical computed case is given in Fig. 7a for $U=-1 \mathrm{~mm} / \mathrm{s}$.

The effect of changing upper platen speed $\dot{U}$ on blank deformation was further investigated and the results are outlined in Fig. 7b and 7c. To clearly demonstrate the effect of upper platen speed on deformation, the three graphs in Fig. 7 were superimposed and the result is given in Fig. 8 which shows little effect of platen speed on blank deformation for the speeds outlined in the figure.

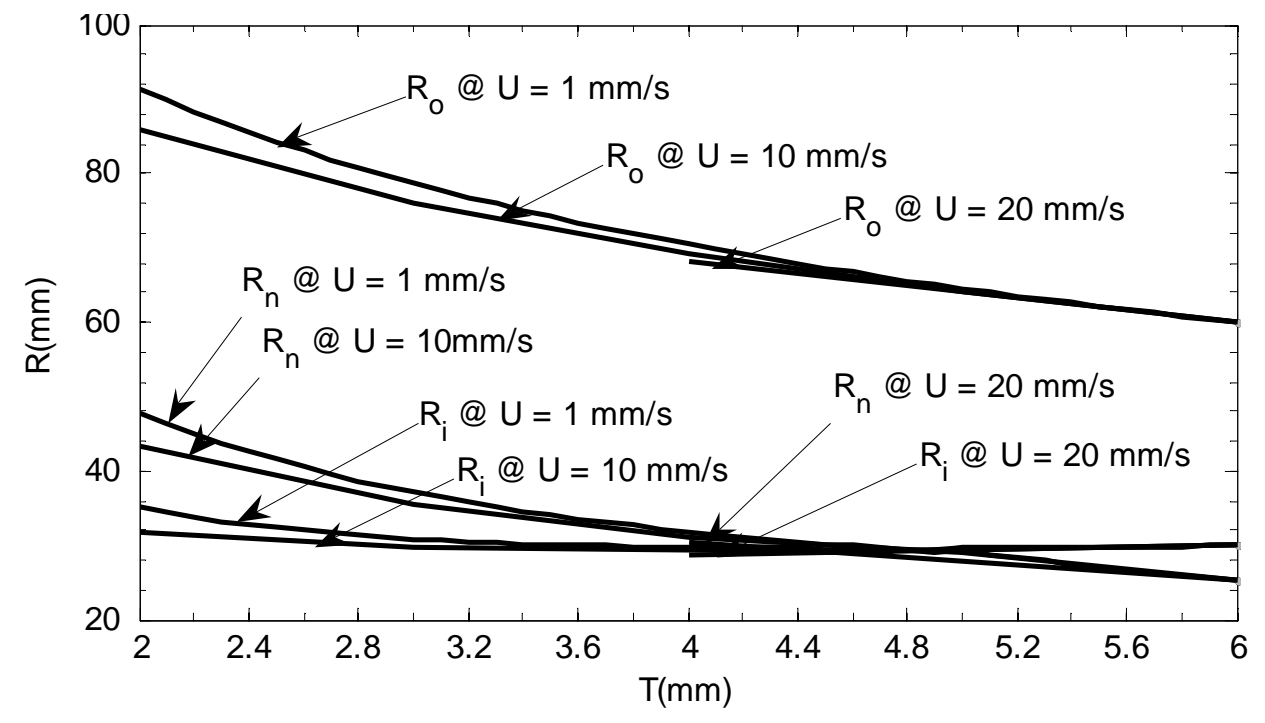

Figure 8: Superposition of results obtained in Fig. 7. 
Relative pressure is computed by either Eq. (17) or Eq. (18), depending upon magnitude of $R_{n} / R_{i}$ and blank geometry. The results are presented in Fig. 9 for different upper platen speeds. It is clear that at the beginning of deformation, the required forging pressure is small. Nevertheless, as the deformation proceeds, pressure increases until final desired blank shape is obtained. The effect of upper platen speed on pressure requirements during deformation is obtained by superposition of the three plots of Fig. 9 and the result is shown in Fig. 10. It suggests that platen speed has little effect on the required forging pressure for the outlined speeds in the figure.
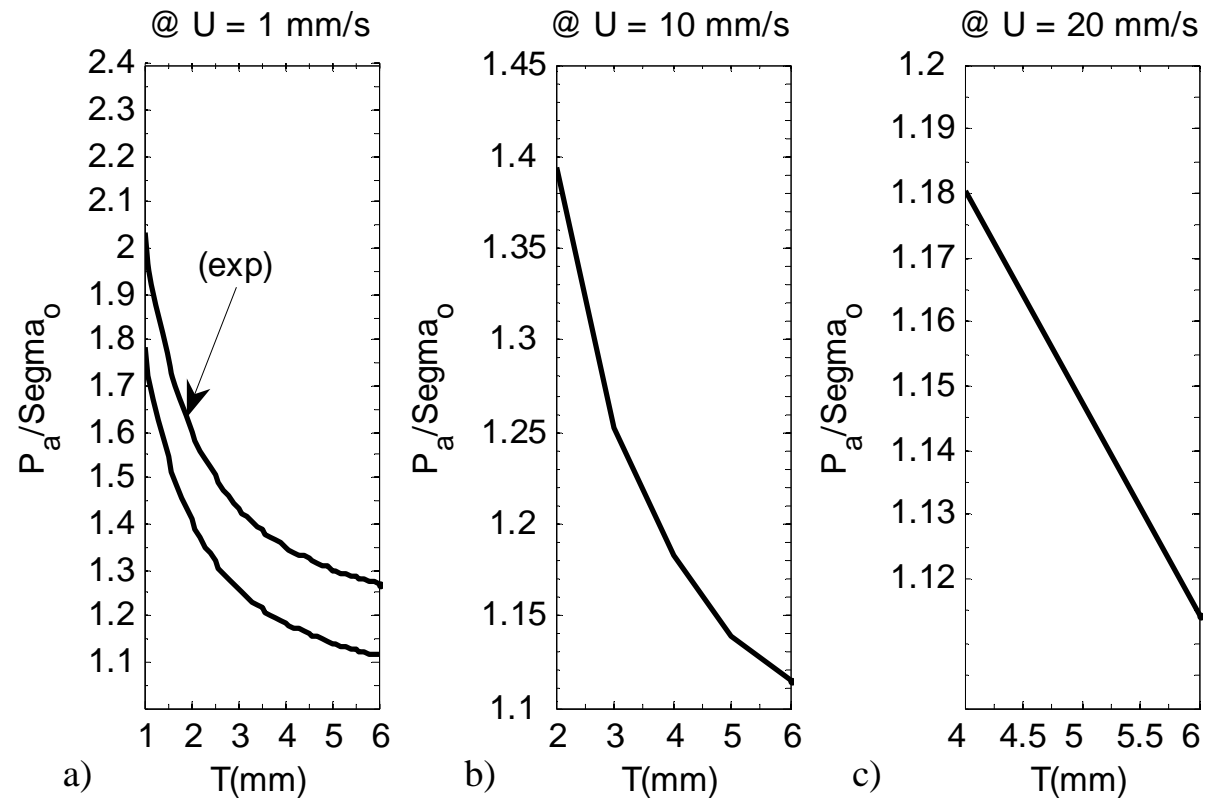

Figure 9: Variation in relative average pressure during deformation at different upper platen velocities.

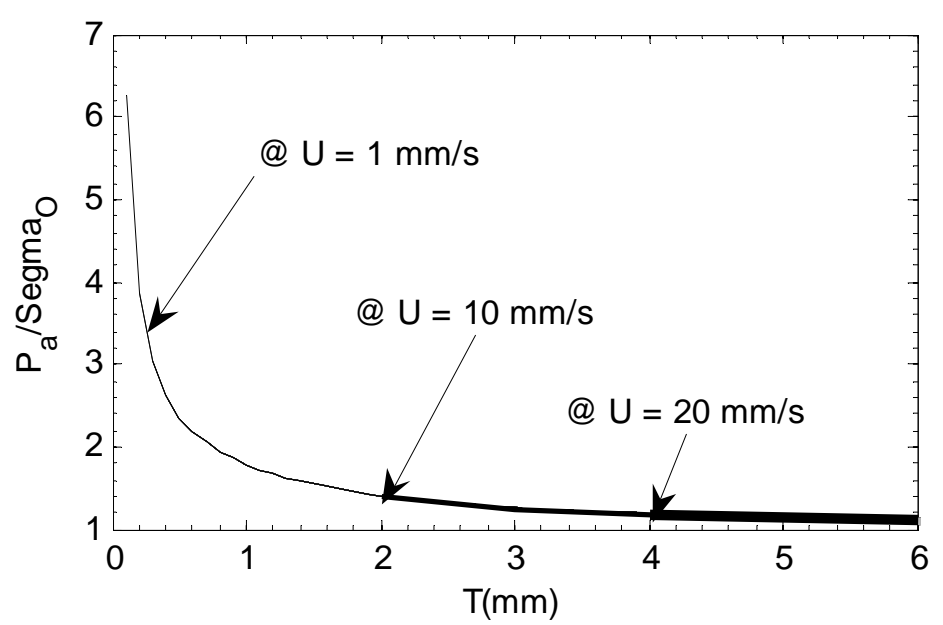

Figure 10: Superposition of results obtained in Fig. 9.

\section{EXPERIMENTAL SUBSTANTIATION}

An experimental set-up was devised to verify the analytical model derived in this study. The deformation of a hollow cylindrical sample (representing the blank) subjected to increasing compression load, was monitored continuously. Both internal and external radii as well as the 
thickness of the sample were monitored during testing by a number of outwardly springloaded Linear Variable Displacement Transducers (LVDT) that were powered by an AC supply (AML/M series of Applied Measurements Ltd., UK). The setup is shown in some detail in Fig. 11. The applied load was measured using the load cell of the hydraulic press used. Change in inside and outside radii was recorded at two perpendicular positions as shown in Fig. 11 to account for possible ovalness due to material anisotropy. Small displacements in the order of $0.0025 \mathrm{~mm}$ were measurable using these probes, and all measurements were fed to a personal computer for analysis of results later on.

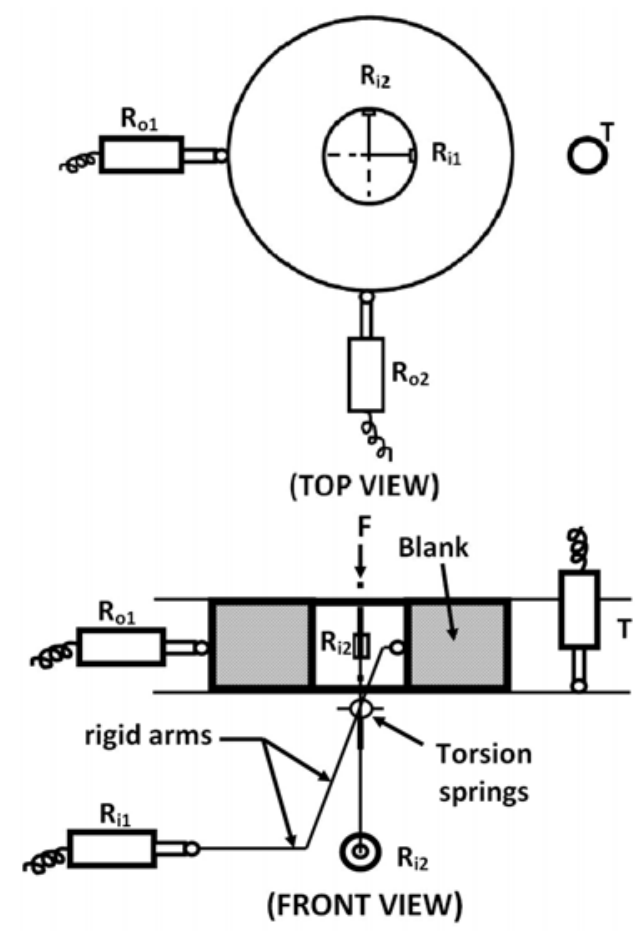

Figure 11: Set-up for deformation measurement using LVDT.

A $99.96 \%$ pure cold rolled aluminium ( $\sigma_{0}=130 \mathrm{MPa}$ ) sample with original dimensions $R_{i}=30 \mathrm{~mm}, R_{o}=60 \mathrm{~mm}, T=6 \mathrm{~mm}$, and a constant velocity of the upper platen of $U_{i}=1 \mathrm{~mm} / \mathrm{s}$ was tested. Experimental results were compared with those obtained analytically in Fig. 7a for $R_{i}$ and $R_{o}$, and in Fig. 9a for relative pressure. It is clear from both figures that the experimental results obtained from the setup agree reasonably well with those obtained analytically. The maximum deviation did not exceed $12 \%$ for the results given in Fig. $7 \mathrm{a}$, and $14 \%$ for those given in Fig. 9a. Much of these deviations are mainly due to two factors. The first is the friction at the blank interfaces which hinders the free movement of surfaces at these locations. The second factor is due to possible barrelling of samples under loading conditions. An in-depth investigation is planned on the latter in a forthcoming study.

\section{CONCLUSIONS}

Forging of cylindrical blanks by open parallel platens can meet practically any shape requirements and offer significant reduction in machining operations. This is possible if the forging process is monitored efficiently. The present study sheds some light on the effect of main parameters that contribute to the success of this type of forging process. The main conclusions that were obtained can be summarized as follows: 
- The continued deformed shape of the blank is mainly governed by its initial dimensions and material as well as the friction coefficient at the blank-platen interface.

- The location of the neutral radius during the forging process influences both the deformed outside $\left(R_{o}\right)$ and inside $\left(R_{i}\right)$ radii of the blank. If the neutral radius becomes less than the inner radius at any stage of deformation, both the inside and outside radii of the sample continue to increase. However, if the neutral radius exceeds the inner radius, then, the outer radius increases while the inner radius decreases. The blank thickness always decreases during deformation, regardless of the magnitude of neutral radius.

- The relative forging pressure on the blank increases with deformation and high friction coefficient at the blank-platen interface.

- The effect of upper platen velocity on blank deformation and relative average forging pressure is negligible for commonly used velocity range.

\section{ACKNOWLEDGEMENT}

The authors are grateful to Kuwait University Research Administration for supporting the study under Grant No. EM 04/06.

\section{REFERENCES}

[1] Bramley, A. N. (1987). Computer aided forging design, CIRP, Vol. 36, 135-138

[2] Mynors, D. J.; Bramley, A. N.; Alan, M. (1997). An examination of manual die design procedures as a precursor to the application of simulation, Proceedings of the International Conference and Exhibition on Design and Production of Dies and Molds, Istanbul, Turkey

[3] Kumar, S.; Ranjan, R. K. (2004). High speed forging of solid powder discs of large slenderness ratio, Sadhana, Vol. 29, Part 5, 525-533

[4] Zhao, G.; Wright, E.; Grandhi, R. V. (1995). Forging preform design with shape complexity control in simulating backward deformation, International Journal of Machine Tools and Manufacture, Vol. 35, No. 9, 1225-1239

[5] Guo, Y.-M.; Nakanishi, K.; Yokouchi, Y. (2005). A non-linear rigid-plastic analysis for metal forming problem using the rigid-plastic point collocation method, Advances in Engineering Software, Vol. 36, No. 4, 234-242

[6] Alfozan, A.; Gunasekera, J. S. (2003). An upper bound elemental technique approach to the process design of axisymmetric forging by forward and backward simulation, Journal of Materials Processing Technology, Vol. 142, No. 3, 619-627

[7] Agrawal, M.; Kumar, S.; Jha, A. K. (1999). High speed forging of hollow metal preforms, Journal of the Institution of Engineers (India), Vol. 80, 8-15

[8] Yang, H.; Zhan, M.; Liu, Y. L.; Xian, F. J.; Sun, Z. C.; Lin, Y.; Zhang, X. G. (2004). Some advanced plastic processing technologies and their numerical simulation, Journal of Materials Processing Technology, Vol. 151, No. 1-3, 63-69

[9] Kopp, R. (1996). Some current development trends in metalforming technology, Journal of Materials Processing Technology, Vol. 60, No. 1-4, 1-9

[10] Hou, J. (1997). A plan-strain UBET analysis of material flow in a filled deep die cavity in closeddie forging, Journal of Materials Processing Technology, Vol. 70, No. 1-3, 103-110

[11] Gunasekera, J. S.; Jia, Z.; Malas, J. C. (1998). Analysis of aluminium extrusion processes using upper bound element technique, Proceedings of the Third World Conference on Integrated Design and Process Technology, Berlin, Germany 